\title{
INVESTIGATION ON THE URMIA LAKE DROUGHT USING SATELLITE ALTIMETRY AND WEATHER REANALYSIS PRODUCTS
}

\author{
F. Sabzehee ${ }^{\text {a, } *, \text { V. Nafisia }}{ }^{\mathrm{a}}$, S. Iran Pour ${ }^{\mathrm{a}}$ \\ ${ }^{a}$ Geomatics Engineering, Faculty of Civil Engineering and Transportation, University of Isfahan, Isfahan, Iran \\ (sabzfarideh, vnafisi, iranpour.siavash)@gmail.com
}

KEY WORDS: Urmia lake, ECMWF, NCEP , Satellite altimetry.

\begin{abstract}
:
The Urmia Lake is located in northwestern Iran. It is the sixth largest salt lake in the world. In the past 14 years, this lake strongly faced to the water level decrease and surface water reduction. Several space-borne techniques have been employed for detecting the hydrological cycle and its inter-annual changes.

The goal of this paper is to investigate weather reanalysis products such as specific humidity of NCEP model and a total column water vapor extracted from ECMWF model and other techniques such as satellite altimetry that have been powerful for the identification of some drought factors of the Urmia Lake.

In this study, we used satellite altimetry data from ENVISAT and CryoSat-2 to monitor the Lake water level and optical satellite imagery to determine the surface water extent of the lake during 2002 to 2014 . Our altimetry and satellite imagery results reveal decrease in height and area of Urmia Lake over the last 14 years. The lake surface area and the water level decreased continuously at approximately $2666 \mathrm{~km}^{2}$ and $3.5 \mathrm{~m}$ respectively.

Moreover, we employed the monthly $0.125^{\circ} \times 0.125^{\circ}$ datasets of the ECMWF data and $2.5^{\circ} \times 2.5^{\circ}$ datasets of the NCEP data to demonstrate amount of water vapor in the atmosphere over the lake. The total column water vapor extracted from ECMWF data and specific humidity of NCEP data show similar behavior. Results indicate that no meaningful correlation between the altimetry data and weather reanalysis models exists. The weather reanalysis models do not indicate descending variations during 2000 until 2014. For interpreting the situation and studying the climate change and man-made impacts on the drought in this region, we need to use ground-based data such as wind speed, precipitation, barometric pressure and temperature.
\end{abstract}

\section{INTRODUCTION}

The Urmia Lake is located in northwestern Iran. It is one of the most saline lakes in the world. It has been reported that in the past 20 years, this lake strongly faced to shrink due to various climatic and anthropogenic reasons (Delju et al., 2013; Karbassi et al., 2010). Delju et al., (2013) stated that a decrease in mean precipitation and an increase in maximum temperature over the past forty years. A causeway was built across the lake during 1979 to 2008 and level water of southern region of the lake basin started drastically decreasing (Eimanifar and Mohebbi, 2007). Many studies have been conducted on causes of variations of level water and drought of Urmia Lake and use of space-borne multi-sensor approach (e.g. Tourian et al., 2015). Abbaspour et al. (2012) provided the hydrodynamic model to simulate the negative variation of water level Urmia Lake according to the bathymetry map.

Hassanzadeh et al. (2012) determined the important factors in the lake's water level decrease. Those factors include the climate change and overuse of surface water resources, the construction of four dams on upstream rivers and reduced precipitation are responsible for $65 \%, 25 \%$ and $10 \%$ respectively.

Duan and Bastiaanssen (2013) determined water volume changes from four satellite altimetry databases and satellite imagery data (the series of Landsat TM/ETM+ imagery) without bathymetry maps in three lakes such as Lake Mead (U.S.A.), Lake Tana (Ethiopia) and Lake IJssel (The Netherlands).
In this study, we use satellite altimetry data from ENVISAT and CryoSat-2 to monitor the lake water level and surface water extent and optical satellite imagery to determine the surface water extent of the lake during 2000 to 2014. We employed the ECMWF and NCEP data to demonstrate amount of water vapor in the atmosphere over the Lake. Results demonstrate that no meaningful correlation between the altimetry data and weather reanalysis models exists. We expressed different scenarios for the reasons of this hazard where additional meteorological data and in situ ground based data and different satellite missions may help us to recognize reasons for the desiccation of the lake.

\section{DATA}

\subsection{Satellite Altimetry and Satellite Optical Imagery}

Satellite altimeters transfer a series of pulses to the Earth's surface in direction towards nadir and a strong reflected pulse receive by the altimeter. There are two types of altimeters as follows: Radar altimeters and Laser altimeters.

Radar altimeters and Laser altimeters send electromagnetic pulses at a microwave frequency (Rosmorduc et al., 2011) and laser frequency at visible and near-infrared wavelengths respectively.

\footnotetext{
* Corresponding author
} 
The radar altimeter was designed for all weather conditions but the laser altimeter is not suitable for rainy/cloudy weather. Measuring the distance (Range) between the satellite and the Earth's surface is considered that the round trip time is propagating at the speed of light (Calmant et al., 2008).

The electromagnetic waves pass through the atmosphere and ionosphere. Accordingly, they are delayed. Then some of corrections should be applied to retrieve the correct Range.

The altimetric height of surface is determined by the equation below:

Height $=$ Altitude of satellite orbit - Range - Correction

A number of corrections such as the displacement of altimeter antenna from the spacecraft center of mass, wet and dry troposphere, the inverse barometer, ocean tide, the solid Earth and pole tide corrections should be applied to the raw altimeter measurements for using at precise geodetic and oceanographic applications (e.g. Birkett,1995; Frappart et al., 2006 a ; Medina et al., 2008).

The ionospheric correction for laser altimetry is ignorable (Frappart et al., 2006a ; Urban et al., 2008).

The altitude of satellite orbit calculates from a reference ellipsoid and an average value over the altimeter footprint(Cretaux \& Birkett, 2006).

The orthometric height can be obtained from a geoid undulation at a point and the ellipsoidal height according to the formula below:

$H=h-N$

Where $\mathrm{H}$ is orthometric height, $\mathrm{h}$ is ellipsoidal height and $\mathrm{N}$ is the geoid undulation. The geoid undulation can be determined from the Earth Gravitational Model (EGM).

Optical satellites record a lot of images of the Earth or other planets with 4 types of resolutions in remote sensing as follows spatial, spectral, temporal and radiometric.

The resolution of satellite images is determined by the instrument used and the altitude of the satellite's orbit (Campbell, 2002).

The Landsat program started on July 23, 1972 until present time and it is the longest running enterprise for acquisition of optical imagery of the Earth in order to use for the different applications in agriculture, cartography, geology, forestly, regional planning, surveillance and education. Each Landsat image is divided into scenses that it is about $185 \mathrm{~km}$ long and $185 \mathrm{~km}$ wide .

In this paper we used satellites altimetry data such as ENVISAT and CRYOSAT2 and Landsat images during 2000-2014 in order to monitor height and area variations on Urmia Lake. In other words, monitoring drying up of Urmia lake with satellite altimetry.

\subsection{Reanalysis Products}

Water vapor is one of the most important atmospheric parameters and is the strongest greenhouse gas. Water vapor has a essential role in the radiative balance of the Earth. So, for weather monitoring, we need access to effective distribution of total column water vapor (TCWV). The behavior of TCWV distribution is similar to the seasonal cycle of the near surface temperature (in the northern hemisphere, a maximum of the total column of water vapor is summer and a minimum in winter ).

ERA-Interim(Dee et al., 2011) is the latest global atmospheric reanalysis produced by the European Center for Medium-Range Weather Forecasts (ECMWF). Archive of this data includes from 1 January 1979 to present. An advantage of using reanalysis data for the comparison is a comprehensive collection of the fundamental climate variables in physically stable frame. We are interested in studying and extracting the ERA-Interim reanalysis data.

There are many horizontal spatial resolution $(3,2.5,1.5,1.125$, $1,0.75,0.5,0.25$ and 0.125 degrees) that distributed according to the user requirements over globe. The various climate indicators derived from ERA-Interim data can be downloaded from this website(https://www.ecmwf.int).

Dataset used in the present study is the ERA-Interm reanalysis produced by the ECMWF that the 6-hourly TCWV data from ECMWF model of ERA-Interim over Lake Urmia has been collected during 2000-2014 periods with a spatial resolution of 0.125 degree . Figure 4 bottom, shows TCWV indicator of ECMWF model during 2000 -2014.

The National Centers for Environmental Prediction (NCEP) product a globally gridded dataset that demonstrates the state of the Earth's atmosphere .The NCEP is a numerical weather prediction (NWP) model that included from 1948 to present.

The data files are temperature (air), specific humidity (shum) and geopotential height (hgt) and etc. that are available at this website(http://rda.ucar.edu/). In order to accomplish this research, daily grid data (shum) with a spatial resolution of $2.5 \times 2.5$ degree every 6 hours during 2000-2014 periods have been extracted from NCEP database.

In this study, we have used dataset of NCEP namely the specific humidity data to obtain information about the surface air humidity. Figure 4 Top, shows SHUM indicator of NCEP between 2000 and 2014.

\section{RESULTS}

Several previous works have studied and investigated the potential reasons for the desiccation of the Urmia Lake. Those reasons may range from increased extraction of the groundwater for agriculture irrigation within the lake's watershed, reduced precipitation, construction of a causeway across the lake, construction of several dams and climate change (Delju et al., 2013; Eimanifar, Mohebbi, 2007; Golabian, 2011; Hassanzadeh et al., 2012; Karbassi et al., 2010; Voss et al., 2013; Zarghami, 2011; Tourian et al., 2015).

Figure 1 shows changes in area of Lake Urmia derived from Landsat imagery from 1972 up to 2014.

As can be seen from the optical satellite imageries in Figure 2, the decrease in surface area is the result of decreasing precipitation from the Global Precipitation Climatology Project (GPCP), high evaporation from ECMWF (see Figure 1). The data of GPCP are available with temporal coverage as monthy values from 1979 until 2017 and spatial coverage include latitude and longitude in a 2.5 -by- 2.5 degrees.

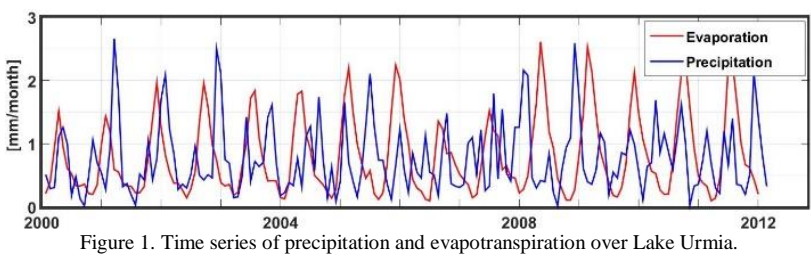

Satellite imagery results reveal a decrease in height and area of Urmia lake over the last 14 years that the water level decreased continuously at approximately $2666 \mathrm{~km}^{2}$ and $3.5 \mathrm{~m}$ respectively. 

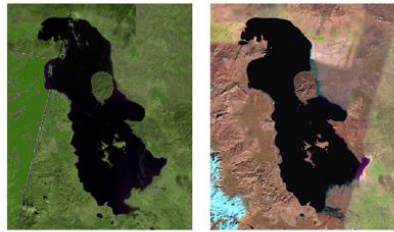

1984

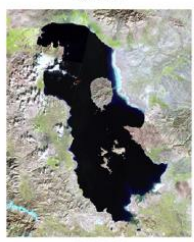

1998

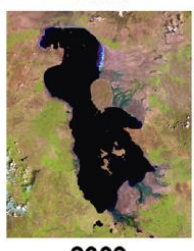

2009

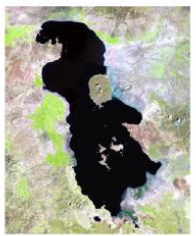

2000

2011



1987

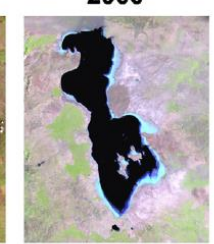

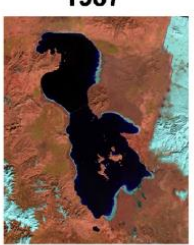

2002

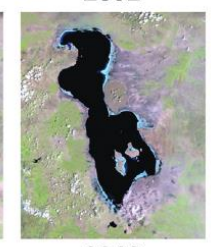

2012

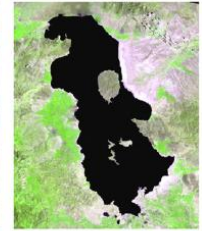

1989

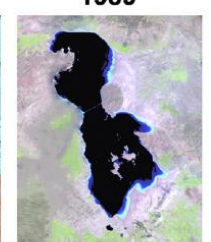

2006

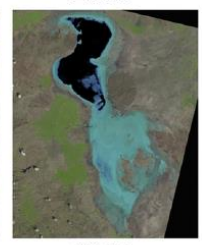

2014
Figure 2. Changes in area of Lake Urmia from October 1972 to August 2014, derived from LandSat imagery (A. AghaKouchak, 2014).

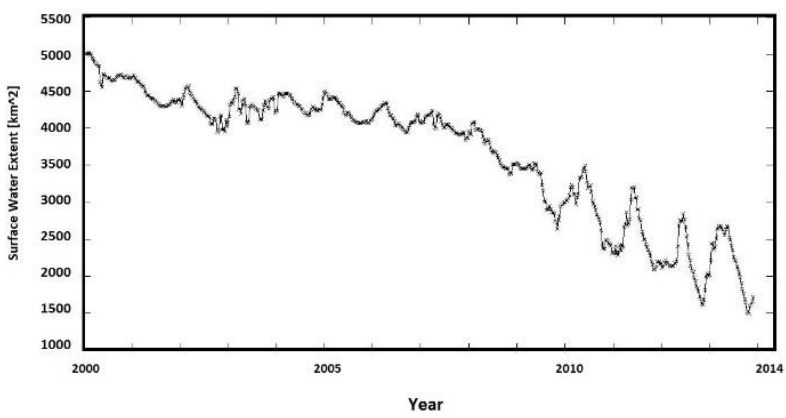

Figure 3. Time series of surface water extent extracted from MODIS imagery during 20002014 years.

As shown in Figure 3, there is a time series of surface water extent extracted from MODIS imagery during 2000-2014. Within the period of 2000 to 2014 the downward trend of the water level has shown to confirm extreme droughts in Region.

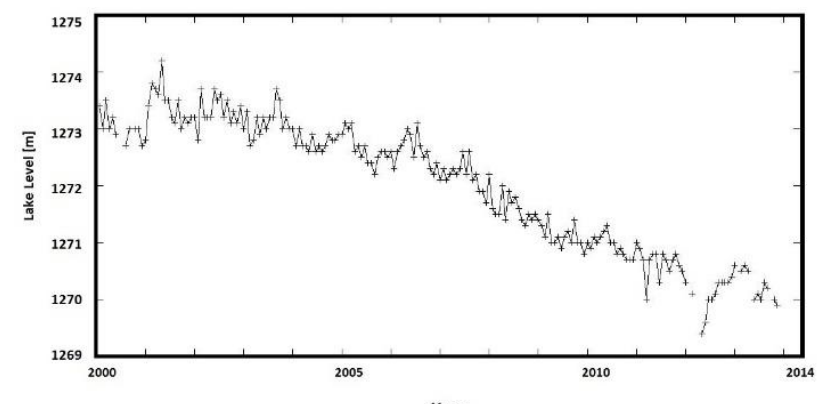

Year

Figure 4. Urmia lake water level time series obtained from ENVISAT, ENVISAT extended mission and CryoSat-2 during 2000 to 2014 years.

Figure 4 indicates time series of water level obtained from ENVISAT, ENVISAT extended mission and CRYOSAT2 since 2000-2014. In present research, MODIS surface reflectance 8day composites with 250 meters spatial resolution using the sinusoidal map projection and also insensitive to the influence of atmospheric conditions such as clouds is applied to record the water level and the area of the Urmia Lake during 2000-2014 (Vermote \& Kotchenova, 2008).

As shown in Figure 5 (top), there is the specific humidity(shum) derived from NCEP over Urmia lake at interested period.

All the years are showing a monotonic manner of the provided datasets. As a result, the recent droughts in this region have not significant impact on time series of shum.

As seen in the Figure 5 (bottom), there is the TCWV indicator of ECMWF dataset during $2000-2014$. The performance of these indices are very similar to each other. So, these datasets do not contain any variation for recognition and prediction of the risk for water scarcity.
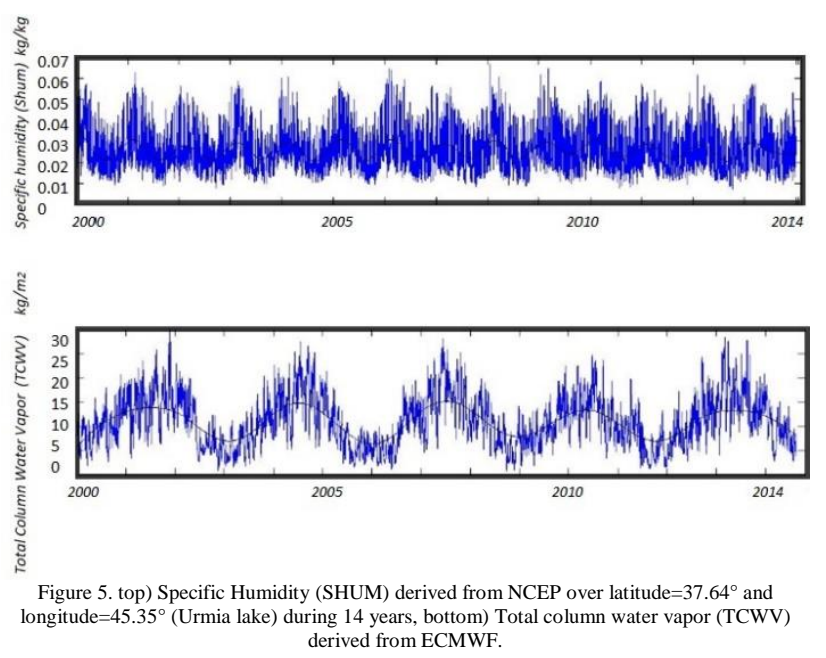

The knowledge about hydrological cycle is very important. The land surface(continent) interchange over the Earth in atmosphere by Evaporation and Precipitation. Evaporated Water from the oceans replace with rain, snow over the Earth. Soil absorbs apart of Rainy Water is called Ground water and other part changed as the irrigation water for plants (Maidment, 1993).

As can be seen in Figure 6, there is a schematically the hydrological cycle and the data sets in this study used in order to a investigation on changes of Urmia Lake water Surface. 


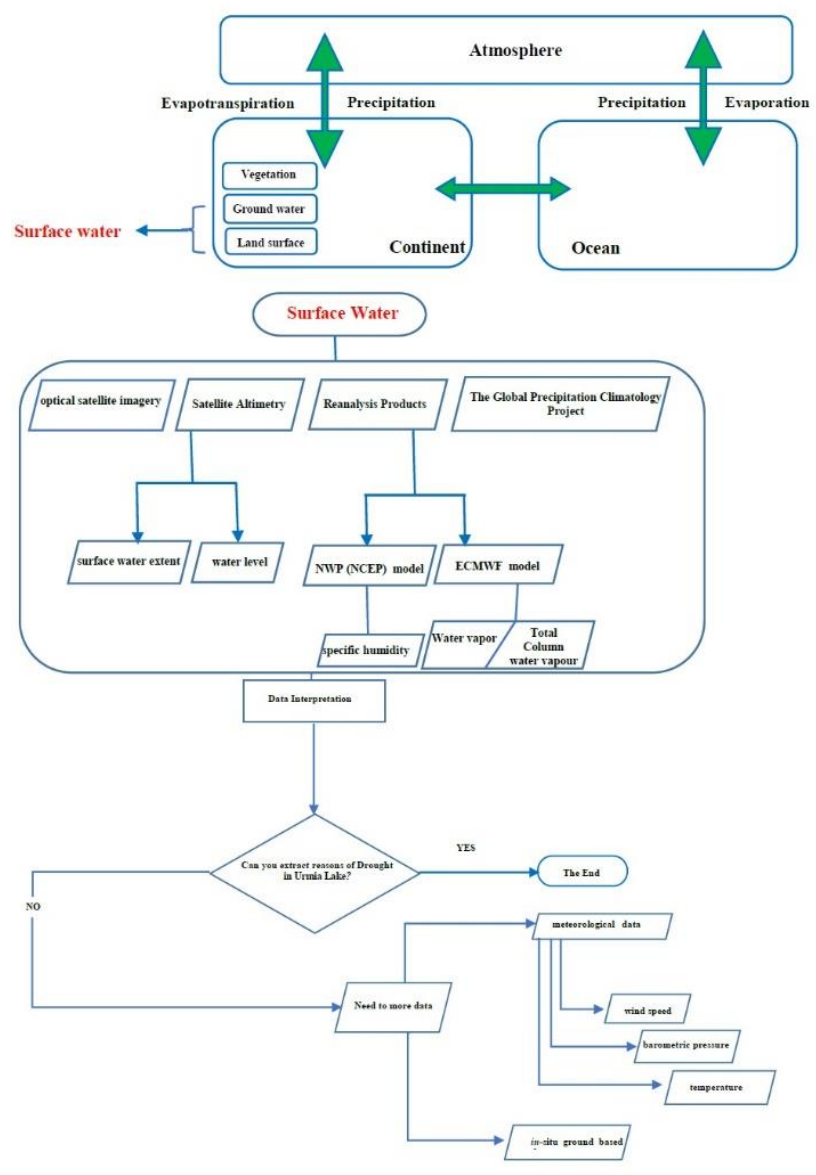

Figure 6. a schematically the hydrological cycle and the data sets used in order to a investigation on changes of Urmia Lake water Surface.

\section{DISCUSSION}

Here we investigate the possible reasons in the difference between satellite altimetry and reanalysis data(TCWV and SHUM):

\section{Scenario 1}

It is possible that evaporation has been increased, but due to air currents and circulations in the atmosphere, it does not show itself in the local humidity of ECMWF data and NCEP data. We may need to use complementary hydrological data such in-situ ground based data such as wind speed, barometric pressure and temperature to investigate the scenario (This scenario is confirmed to some extent by Figure 1).

\section{Scenario 2}

It is possible that the evaporation over the lake did not increase significantly but is used overestimated from ground water and other reasons, this hazard is occurred. Then, we need to know the other complementary sources for the correct interpretation of the situation.

\section{Scenario 3}

It is possible that the global models like NCEP and ECMWF are not very good representatives for what happens in the regional scales. Therefore, local measurements might be required for better understanding of the geophysical processes in the region.

As a result, collecting meteorological data and in situ ground based data and data from different satellite missions will help us to recognize and better understand the reasons for the desiccation of the lake.

\section{REFERENCES}

AghaKouchak A., 2014. Aral Sea syndrome desiccates Lake Urmia: Call for action. Journal of Great Lakes Research 41: 307311.

Birkett, C. M.,1995. The contribution of TOPEX/POSEIDON to the global monitoring of climatically sensitive lakes. Journal of Geophysical Research-Oceans, 100, 25179-25204.

Calmant, S., Seyler, F., \& Crétaux, J. F. ,2008. Monitoring continental surface waters by satellite altimetry. Surveys in Geophysics, 29, 247-269.

Campbell, J. B., 2002. Introduction to Remote Sensing. New York London: The Guilford Press.

Crétaux, J. F., \& Birkett, C., 2006. Lake studies from satellite radar altimetry. Comptes Rendus Geosciences, 338, 1098-1112.

Dee, D. P., et al., 2011. The ERA-Interim reanalysis: Configuration and performance of the data assimilation system, Q. J. R. Meteorol. Soc.,137, 553-597, doi:10.1002/qj.828.

Delju A., Ceylan A., Piguet E., Rebetez M., 2013. Observed climate variability and change in Urmia Lake Basin, Iran. Theoretical and Applied Climatology,111(1-2), 285-296.

Duan, Z., \& Bastiaanssen, W. G. M., 2013. First results from Version 7 TRMM 3B43 precipitation product in combination with a new downscaling-calibration procedure. Remote Sensing of Environment, 131, 1-13.

Eimanifar A., Mohebbi F., 2007. Urmia lake (Northwest Iran): A brief review. Saline Systems, 3-5.

Frappart, F., Calmant, S., Cauhope, M., Seyler, F., \& Cazenave, A., 2006a. Preliminary results of ENVISAT RA-2-derived water levels validation over the Amazon basin. Remote Sensing of Environment, 100, 252-264.

Golabian H., 2011. Urumia lake: Hydro-ecological stabilization and permanence. In V.Badescu, \& R.B. Cathcart (Eds.), Macroengineering seawater in unique environments.Environmental Science and Engineering. 365-397. Springer Berlin Heidelberg.

Hassanzadeh E., Zarghami M., Hassanzadeh Y., 2012. Determining themain factors in declining the urmia lake level by using system dynamics modeling. Water Resources Management, 26(1), 129-145.

Karbassi A., Bidhendi G.N., Pejman A., Bidhendi M.E., 2010. Environmental impacts of desalination on the ecology of Lake Urmia. Journal of Great Lakes Research, 36(3),419-424.

Maidment, D. R., 1993. Handbook of hydrology, McGraw-Hill.

Medina, C. E., Gomez-Enri, J., Alonso, J. J., \& Villares, P., 2008. Water level fluctuations derived from ENVISAT Radar Altimeter (RA-2) and in-situ measurements in a subtropical waterbody: Lake Izabal (Guatemala). Remote Sensing of Environment, 112,3604-3617.

Rosmorduc, V., Benveniste, J., Lauret, O., Maheu, C., Milagro, M., \& Picot, N., 2011. In J.Benveniste, \& N. Picot (Eds.), Radar altimetry tutorial. 
Tourian M.J, Elmi O., Chen Q., Devaraju B., Roohi Sh., Sneeuw N., 2015. A spaceborne multisensor approach to monitor the desiccation of Lake Urmia in Iran, Remote Sensing of Environment 156, 349-360.

Urban, T. J., Schutz, B. E., \& Neuenschwander, A. L., 2008. A survey of ICESat coastal altimetry applications: Continental coast, open ocean island, and inland river. Terrestrial Atmospheric and Oceanic Sciences, 19, 1-19.

Vermote, E.F., \& Kotchenova, S.Y., 2008. MOD09 (surface reflectance) user's guide. Tech. Rep. 1.1. MODIS Land Surface Reflectance Science Computing Facility.

Voss K.A., Famiglietti J.S., Lo M., de Linage C., Rodell M., Swenson S.C., 2013. Groundwater depletion in the Middle East from GRACE with implications for transboundary water management in the Tigris-Euphrates-western Iran region. Water Resources Research, 49(2), 904-914.

Zarghami M., 2011. Effective watershed management; case study of Urmia Lake, Iran.Lake and Reservoir Management, 27(1), 87-94. 